\title{
Hemochromatosis (HFE) gene mutations in Brazilian chronic hemodialysis patients
}

F.V. Perícole, M.A.V.R. Alves, S.T.O. Saad and F.F. Costa
Divisões de Nefrologia e de Hematologia, Departamento de Medicina Interna, Faculdade de Ciências Médicas, Universidade Estadual de Campinas, Campinas, SP, Brasil
Correspondence

F.F. Costa

Departamento de Clínica Médica

FCM, UNICAMP

13083-970 Campinas, SP

Brasil

Fax: +55-19-3289-1089

E-mail: ferreira@unicamp.br

Research supported by CNPq and FAPESP.

Received September 23, 2004 Accepted June 27, 2005

\begin{abstract}
Patients with chronic renal insufficiency (CRI) have reduced hemoglobin levels, mostly as a result of decreased kidney production of erythropoietin, but the relation between renal insufficiency and the magnitude of hemoglobin reduction has not been well defined. Hereditary hemochromatosis is an inherited disorder of iron metabolism. The importance of the association of hemochromatosis with treatment for anemia among patients with CRI has not been well described. We analyzed the frequency of the $\mathrm{C} 282 \mathrm{Y}$ and H63D mutations in the HFE gene in 201 Brazilian individuals with CRI undergoing hemodialysis. The analysis of the effects of HFE mutations on iron metabolism and anemia with biochemical parameters was possible in 118 patients of this study (hemoglobin, hematocrit, ferritin levels, transferrin saturation, and serum iron). A C282Y heterozygous mutation was found in $7 / 201(3.4 \%)$ and H63D homozygous and heterozygous mutation were found in $2 / 201(1.0 \%)$ and 46/201 (22.9\%), respectively. The allelic frequencies of the HFE mutations ( 0.017 for $\mathrm{C} 282 \mathrm{Y}$ mutation and 0.124 for H63D mutation) did not differ between patients with CRI and healthy controls. Regarding the biochemical parameters, no differences were observed between HFE heterozygous and mutationnegative patients, although ferritin levels were not higher among patients with the H63D mutation $(\mathrm{P}=0.08)$. From what we observed in our study, C282Y/H63D HFE gene mutations are not related to degrees of anemia or iron stores in CRI patients receiving intravenous iron supplementation $(\mathrm{P}>0.10)$. Nevertheless, the present data suggest that the H63D mutation may have an important function as a modulating factor of iron overload in these patients.
\end{abstract}

Anemia associated with chronic renal insufficiency (CRI) has clinical and public health importance (1). Patients with CRI have reduced hemoglobin levels, mostly as a result of decreased kidney production of erythropoietin, although the relation between the degree of renal insufficiency and the
Key words

- HFE

- Chronic renal insufficiency

- Anemia

- Iron metabolism magnitude of hemoglobin reduction is not well understood. The high efficacy and benefit of recombinant human erythropoietin in the treatment of renal anemia have been documented in numerous studies, $(1,2)$.

Absolute and functional iron deficiencies are common in hemodialysis patients treated 
with recombinant human erythropoietin $(2,3)$. Maintaining normal iron homeostasis is essential for the organism since both iron deficiency and iron excess are associated with cellular dysfunction (4). Ferritin is the major iron storage protein, mostly in the cells of the macrophage-monocyte system (especially in the liver, spleen, bone marrow, and skeletal muscle) (5). There was a good correlation between the small amount of ferritin found in serum and body iron stores (6).

Hereditary hemochromatosis $(\mathrm{HH})$ is an inherited disorder of iron metabolism, common among populations of Northern European origin, in which intestinal iron absorption is excessive irrespective of body iron stores (7). In 1996, Feder et al. (8) described two mutations in the HFE gene located on chromosome 6 as one of the defects responsible for hemochromatosis.

The mutation found to be associated with $\mathrm{HH}$ was a single base change in exon 4 , resulting in the substitution of tyrosine for cysteine at amino acid 282 of the unprocessed protein (C282Y). The proportion of $\mathrm{HH}$ patients homozygous for $\mathrm{C} 282 \mathrm{Y}$ varies, ranging from $64 \%$ in Italy to $100 \%$ in Australia (9). The other is a missense mutation at nucleotide 187 of the HFE open reading frame, resulting in the substitution of histidine for aspartate at amino acid 63 (H63D). It is found in $15-40 \%$ of Caucasians and H63D homozygosity leads to only a slight increased risk for iron loading. Both mutations are generally expressed only in homozygosity, but there are few studies concerning the effect of these mutations on patients with CRI and their relation with supplementation therapy with high doses of intravenous iron (10).

We determined the frequency of the C282Y and H63D mutations in Brazilian individuals with chronic renal insufficiency undergoing hemodialysis and the effects of HFE mutations, iron metabolism and anemia.
We analyzed 201 patients with CRI undergoing chronic hemodialysis at the University Hospital of Campinas, comprising 118 men (58.7\%) and 83 women (41.3\%). Their mean age was 45.5 years (range 14-82 years). Ninety-one blood donors (50 men and 41 women) were included as healthy controls regardless of ethnic classification. The study was approved by the Ethics Committee of the Hospital and all patients gave written informed consent to participate

The $\mathrm{C} 282 \mathrm{Y}$ and H63D mutations were detected by restriction enzyme analysis of PCR-amplified DNA extracted from peripheral blood leukocytes (11). The digested products were run on $3.5 \%$ agarose gels and stained with ethidium bromide.

The possible relationship between HFE mutations and iron metabolism was determined using the hematological and biochemical parameters of 118 of the patients under study (hemoglobin, hematocrit, ferritin levels, transferrin saturation, and serum iron).

Data were analyzed statistically with the Epi-Info 6.0 software using Fisher's exact test and the Student $t$-test, with the level of significance set at $\mathrm{P}<0.05$.

Heterozygous $\mathrm{C} 282 \mathrm{Y}$ mutation was found in 7/201 patients (3.4\%) and H63D homozygous and heterozygous mutation were found in $2 / 201(1.0 \%)$ and $46 / 201$ (22.9\%), respectively. The allelic frequencies of the $H F E$ mutations ( 0.017 for $\mathrm{C} 282 \mathrm{Y}$ mutation and 0.124 for H63D mutation) did not differ between patients with CRI and healthy controls (0.011 for C282Y mutation and 0.098 for H63D mutation). There were no compound heterozygous patients.

The biochemical and hematological parameters of 118 patients are presented in Tables 1 and 2, divided according to genotype. No differences were observed between C282Y HFE heterozygous and HFE normal patients with CRI (Table 1). There was no association between mutation and serum iron, transferrin saturation, hemoglobin and hematocrit levels $(\mathrm{P}>0.10)$ for the H63D muta- 
tion (Table 2) but, as expected, there was a relation between ferritin and transferrin saturation $(\mathrm{P}<0.001)$. Interestingly, in our study, ferritin levels were not higher among patients with H63D mutation ( $\mathrm{P}=0.08)$. The study of larger number of patients should clarify this possibility. In addition, the highest serum ferritin level and transferrin saturation were noticed in the only H63D homozygous patient analyzed. A previous study from Italy with 132 patients with CRI on dialysis also did not find a relation between biochemical parameters and C282Y/H63D mutations (12).

The results presented here indicate an influence, not yet determined, of the H63D mutation in patients with CRI. This mutation appears to lead to only a slightly ( 4-fold) increased risk for iron loading when in homozygosity (9), but it may be more important among CRI patients probably due to supplementation with high doses of intravenous iron. The patients with the mutation would be more susceptible to an iron overload because of the genetic susceptibility and excessive doses of intravenous iron administered to CRI patients, as previously proposed $(13,14)$.

Taken together, the present data do not determine if the H63D mutation is a factor modifying the iron balance among patients with CRI undergoing hemodialysis and intravenous iron therapy, therefore suggesting
Table 1. Biochemical parameters of 118 patients with chronic renal insufficiency, classified by C282Y genotype in the HFE gene.

\begin{tabular}{lrc}
\hline C282Y mutation & C282Y negative & C282Y heterozygous \\
\hline Serum iron $(\mu \mathrm{g} / \mathrm{dL})$ & $74.5 \pm 45.27(88)$ & $64 \pm 29.46(3)$ \\
Ferritin $(\mathrm{ng} / \mathrm{mL})$ & $743.9 \pm 637.44(90)$ & $207 \pm 204.41(3)$ \\
Transferrin saturation $(\%)$ & $32 \pm 17.80(73)$ & $26.4(1)$ \\
$\mathrm{Hb}(\mathrm{g} / \mathrm{dL})$ & $10.7 \pm 1.92(97)$ & $10.1 \pm 2.85(4)$ \\
$\mathrm{Ht}(\%)$ & $32.6 \pm 5.88(96)$ & $30.3 \pm 9.15(4)$
\end{tabular}

Data are reported as median \pm SD. The number of patients analyzed is given in parentheses. There was no statistically significant difference between groups (chisquare test).

Table 2. Biochemical parameters of 118 patients with chronic renal insufficiency, classified by H63D genotype in the HFE gene.

\begin{tabular}{lccr}
\hline H63D mutation & $\begin{array}{c}\text { H63D } \\
\text { negative }\end{array}$ & $\begin{array}{c}\text { H63D } \\
\text { heterozygous }\end{array}$ & $\begin{array}{c}\text { H63D } \\
\text { homozygous }\end{array}$ \\
\hline Serum iron $(\mu \mathrm{g} / \mathrm{dL})$ & $76.5 \pm 47.31(72)$ & $62 \pm 24.11(19)$ & $153(1)$ \\
Ferritin $(\mathrm{ng} / \mathrm{mL})$ & $703 \pm 591.07(75)$ & $1004.7 \pm 667.24(18)$ & $2493(1)$ \\
Transferrin saturation $(\%)$ & $31.6 \pm 17.94(59)$ & $28 \pm 15.64(15)$ & $68.9(1)$ \\
$\mathrm{Hb}(\mathrm{g} / \mathrm{dL})$ & $10.7 \pm 2.07(80)$ & $10.7 \pm 1.41(21)$ & $9.1(1)$ \\
$\mathrm{Ht}(\%)$ & $32.4 \pm 6.22(78)$ & $32.8 \pm 4.94(22)$ & $28(1)$ \\
\hline
\end{tabular}

Data are reported as median \pm SD. The number of patients analyzed is given in parentheses. There was no statistically significant difference between groups (chisquare test).

the need of a further multicentric study in order to clarify this possibility. If this hypothesis is confirmed, patients with H63D mutation should be closely monitored for ferritin in order to prevent iron overload.

\section{References}

1. Hsu CY, McCuloch CE \& Curhan GC (2002). Epidemiology of anemia associated with chronic renal insufficiency among adults in the United States: Results from the Third National Health and Nutrition Examination Survey. Journal of the American Society of Nephrology, 13: 504-510.

2. Sunder-Plassmann G \& Hörl WH (1997). Erythropoietin and iron. Clinical Nephrology, 47: 141-157.

3. Besarab A, Frinak S \& Yee J (1999). An indistinct balance: the safety and efficacy of parenteral iron therapy. Journal of the American Society of Nephrology, 10: 2029-2043.

4. Anonymous (2001). IV. NKF-K/DOQI Clinical Practice Guidelines for Anemia of Chronic Kidney Disease: update 2000. American
Journal of Kidney Diseases, 37 (Suppl 1): S182-S238.

5. Kaltwasser JP \& GottSchalk R (1999). Erythropoietin and iron. Kidney International, 55 (Suppl 69): S49-S56.

6. Cook JD, Lipschitz DA, Miles LEM et al. (1974). Serum ferritin as a measure of iron stores in normal subjects. American Journal of Nutrition, 27: 681-687.

7. Townsend A \& Drakesmith H (2002). Role of HFE in iron metabolism, hereditary haemochromatosis, anaemia of chronic disease and secondary iron overload. Lancet, 359: 786-790.

8. Feder JN, Gnirke A, Thomas W et al. (1996). A novel MHC class Ilike gene is mutated in patients with hereditary haemochromatosis. Nature Genetics, 3: 399-408. 
9. Fleming RE \& Sly WS (2002). Mechanisms of iron accumulation in hereditary hemochromatosis. Annual Review of Physiology, 64: 663680.

10. Beutler E, Gelbart T, West C et al. (1996). Mutation analysis in hereditary hemochromatosis. Blood Cells, Molecules and Diseases, 22: 187-194.

11. Agostinho MF, Arruda VR, Basseres DS et al. (1999). Mutation analysis of the HFE gene in Brazilian populations. Blood Cells,
Molecules and Diseases, 25: 324-327.

12. Canavese C, Bergamo D, Barbieri S et al. (2002). Clinical relevance of hemochromatosis-related HFE C282Y/H63D gene mutations in patients on chronic dialysis. Clinical Nephrology, 58: 438-444.

13. Cuthbert JA (1997). Iron, HFE and hemochromatosis update. Journal of Investigative Medicine, 45: 518-529.

14. Schaefer RM \& Bahner U (2000). Iron metabolism in rhEPO-treated hemodialysis patients. Clinical Nephrology, 53 (Suppl 1): S65-S68. 